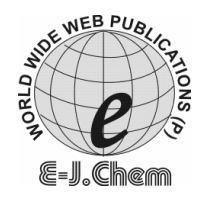

\title{
Cerium(III)-Selective Membrane Electrode Based on Dibenzo-24-crown-8 as a Neutral Carrier
}

\author{
SUSHEEL K MITTAL*, S.K ASHOK KUMAR and HARISH K SHARMA ${ }^{\S}$ \\ School of Chemistry \& Biochemistry, Thapar University, Patiala 147004, India. \\ ${ }^{\S}$ PG Department of Chemistry, M.M. University, Mullana (Ambala) 133203, India. \\ shr_harish@yahoo.com
}

Received 16 August 2009; Accepted 10 October 2009

\begin{abstract}
Cerium(III)-selective membrane electrodes have been prepared using dibenzo-24-crown-8 (DB24C8) as an electroactive material. A membrane having a composition: DB24C8 (4.5\%), plasticizer (NPOE, 62.5\%) and PVC (33\%) gives the best performance. It works well over a wide $\mathrm{Ce}(\mathrm{III})$ ion-concentration range of $1 \times 10^{-5} \mathrm{M}$ to $1 \times 10^{-1} \mathrm{M}$ with a Nernstian slope of $19.0 \mathrm{mV} /$ decade and a detection limit of $3 \times 10^{-5} \mathrm{M}$. It has a fast response time of 20 seconds and has an average lifetime of four months. The internal solution concentration does not have a significant effect on the response of the electrode except for a change in intercept of the calibration curves. The working $\mathrm{pH}$ range for $\mathrm{Ce}(\mathrm{III})$ solutions $\left(1 \times 10^{-2} \mathrm{M}\right.$ and $\left.1 \times 10^{-3} \mathrm{M}\right)$ is 3.5-8.0. The proposed sensor shows a good selectivity for cerium(III) with respect to alkali, alkaline earth, some transition and rare earth metal ions that are normally present along with cerium in its ores. The proposed sensor was investigated in partially non-aqueous media using acetone, methanol and DMSO mixtures with water. The electrode was further used as an indicator electrode for the potentiometric titration of $\mathrm{Ce}(\mathrm{III})$ solution against oxalic acid solution.
\end{abstract}

Keywords: Cerium(III), ISE, Potentiometric sensor, DB24C8, FIM, Selectivity coefficients, Potentiometric titration.

\section{Introduction}

Cerium is a member of lanthanum group of elements and the most abundant of them. It is found in monazite, ceric bastnaesite and silicate rocks. It is widely used in production of ductile iron, cast iron and some stainless steels ${ }^{1}$. The use of cerium is still growing due to the fact that it is suited to produce catalysts and to polish glasses.

Cerium is mostly dangerous in the working environment due to the fact that damps and gasses can be inhaled with air. This can cause lung embolisms, especially during long-term exposure. Cerium can be a threat to liver when it accumulates in body. It is noteworthy that despite the urgent need for a cerium(III) sensor for the potentiometric monitoring of cerium in many industrial, geological and chemical samples ${ }^{2-3}$, there are only a few reports ${ }^{4-7}$ of cerium(III)-selective electrodes in literature. 
Lanthanides are expected to form stable complexes with various macrocyclic ligands, similar to alkali and alkaline earth metals, because of the similarity of radii between lanthanides and $\mathrm{Na}^{+}$ or $\mathrm{Ca}^{2+}$ ions. In fact, it was mentioned in the first report on crown ethers by Pedersen $(1967)^{8}$ that some crown ethers formed complexes with $\mathrm{La}(\mathrm{III})$ and $\mathrm{Ce}(\mathrm{III})$ in solution. However, attention has been focused, mainly on complexes of alkali and alkaline earth metal ions.

The advantages of ion-selective electrodes (ISE) over many other methods ${ }^{9-17}$ for cation and anion detection are their easy handling, non-destructive analysis and inexpensive sample preparation. The function of a crown ether as an electroactive material for ion-selective electrodes is based on such diverse parameters as the structure and cavity size of the ligand, the stability and selectivity of its metal ion complex, its solubility and the ability to extract the metal ion into the membrane phase. In this paper, we report the determination of Ce(III) ions based on dibenzo-24crown-8 [DB24C8] as a neutral carrier to construct a PVC-based membrane electrode.

\section{Experimental}

Reagents, like dibenzo-24-crown-8 (DB24C8) and o-nitro phenyl octyl ether (o-NPOE), were procured from Sigma-Aldrich. Cerium chloride and other rare earth chlorides were purchased from Indian Rare Earth Chemicals Ltd., India. Since all the chemicals were of analytical grade, these were used as such. All stock solutions of rare earth metal ions were standardized with EDTA using xylenol orange as an indicator. Double distilled deionized water was used throughout the experiments.

\section{Instruments used}

ISFET 701 pocket $\mathrm{pH}$ meter (Delta TRAK, INC., USA Model 24003) was used to measure $\mathrm{pH}$ of the solutions. Emf measurements were made using a digital potentiometer (Equiptronics EQ-602, Mumbai, India) with an accuracy of $\pm 0.1 \mathrm{mV}$.

\section{Preparation of PVC membrane}

A homogenized mixture of about $1 \mathrm{~g}$ with components: PVC, 33\%; DB24C8, 4.5\%; $o$-NPOE, $62.5 \%$ was dissolved in $2-3 \mathrm{~mL}$ of THF at room temperature. The viscous solution thus obtained was poured in a glass ring of $30 \mathrm{~mm}$ diameter placed on a dust free Pyrex glass plate $^{18}$. The solvent was allowed to evaporate slowly for about $24 \mathrm{~h}$ at room temperature. To obtain membranes with similar characteristics, viscosity of the casting solution and the rate of solvent evaporation were controlled so that thickness and morphology of membranes remain almost unchanged. The prepared membranes were removed from the glass plate and circular pieces of $2.0 \mathrm{~cm}$ diameter were cut.

\section{EMF measurements}

Membranes were fixed to one end of the glass tube of $1.8 \mathrm{~cm}$ (internal diameter) using an epoxy resin as adhesive. These were then equilibrated with $\mathrm{Ce}^{3+}$ solution $(0.1 \mathrm{M})$ for 12 hours. The tube was filled $1 / 4^{\text {th }}$ with cerium(III) chloride solution $(0.1 \mathrm{M})$ and immersed in a beaker containing the test solution of varying concentration of $\mathrm{Ce}^{3+}$ keeping the level of inner filling solution higher than the level of the test solution to avoid any reverse diffusion of the electrolyte. All the emf measurements were carried out using the following cell assembly:

$$
\mathrm{SCE}\left|\mathrm{Ce}^{3+}(0.1 \mathrm{M})\right| \mid \text { Membrane }|| \mathrm{Ce}^{3+} \text { (test solution) | SCE }
$$

Potentiometric measurements were made using digital potentiometer (Equiptronics EQ602, Mumbai, India), at $25 \pm 0.1^{\circ} \mathrm{C}$. Activities were calculated according to Debye - Huckel equation $^{18}$. Test solutions were obtained by gradual dilution of the stock solution. Potential measurements were made in unbuffered solutions to avoid interference from any foreign ion. 


\section{Storage of electrodes}

The DB24C8 based electrodes were stored in distilled water when not in use for more than one day. These were activated with $\mathrm{Ce}(\mathrm{III})$ solution $(0.1 \mathrm{M})$ by keeping immersed in the solution for two hours, before use, to compensate for any loss of metal ions in the membrane phase that might have taken place due to a long storage in distilled water. Electrodes were then washed thoroughly with distilled water before use.

\section{Results and Discussion}

Ion-selective electrodes work on the principle of measurements at zero current. The membranes are fixed in the electrode assembly and all measurements are made in a concentration cell. The concentration of the electrolyte on the inner side of the membrane is fixed at $0.1 \mathrm{M}$ of $\mathrm{Ce}(\mathrm{III})$ ions while on the other side of the membrane it varies from $10^{-8} \mathrm{M}$ to $10^{-1} \mathrm{M}$. The potential difference can be measured between two identical reference electrodes placed in the two phases. No ionic strength adjustment buffer was used to avoid any unwanted foreign ions from the buffer. Moreover, the ionic strength does not change much during the study as experiments are done in dilute solutions only in the major part of the measuring range of the electrode (i.e., $10^{-6} \mathrm{M}-10^{-1} \mathrm{M}$ ).

\section{Optimization of membrane ingredients}

The effect of membrane composition on the response of the electrode was investigated. For this purpose, performance characteristics, like slope of the calibration curve, measurement range and detection limit, were studied. The results are shown in Table 1. It is evident from this table that the electrode 6 with the ratio PVC:o-NPOE:DB24C8 as 33\%:62.5\%:4.5\%, shows the best performance with a near Nernstian slope of $19.0 \mathrm{mV}$ per decade. This electrode is used for the subsequent studies.

Table 1. Optimization of membrane ingredients for DB24C8 based membranes

\begin{tabular}{ccccccc}
\hline S.No. & $\begin{array}{c}\text { PVC } \\
\text { Wt\% }\end{array}$ & $\begin{array}{c}\text { Plasticizer } \\
\text { Wt\% }\end{array}$ & $\begin{array}{c}\text { Ionophore } \\
\text { Wt\% }\end{array}$ & $\begin{array}{c}\text { Slope } \\
\text { mV/decade }\end{array}$ & $\begin{array}{c}\text { Working } \\
\text { range, M }\end{array}$ & $\begin{array}{c}\text { Detection } \\
\text { Limit, M }\end{array}$ \\
\hline 1 & 33 & 67 & 0 & 10 & $1 \times 10^{-4}-1 \times 10^{-1}$ & $8 \times 10^{-4}$ \\
2 & 33 & 66 & 1 & 17 & $1 \times 10^{-4}-1 \times 10^{-1}$ & $3 \times 10^{-4}$ \\
3 & 33 & 65 & 2 & 20 & $1 \times 10^{-5}-1 \times 10^{-1}$ & $2 \times 10^{-4}$ \\
4 & 33 & 64 & 3 & 20 & $1 \times 10^{-5} 1 \times 10^{-1}$ & $8 \times 10^{-5}$ \\
5 & 33 & 63 & 4 & 20 & $1 \times 10^{-5}-1 \times 10^{-1}$ & $5 \times 10^{-5}$ \\
6 & 33 & 62.5 & 4.5 & 21 & $1 \times 10^{-5}-1 \times 10^{-1}$ & $3 \times 10^{-5}$ \\
7 & 33 & 62 & 5 & 39 & $5 \times 10^{-5}-1 \times 10^{-1}$ & $5 \times 10^{-5}$ \\
8 & 33 & 61 & 6 & 34 & $5 \times 10^{-4}-1 \times 10^{-1}$ & $5 \times 10^{-5}$ \\
9 & 33 & 63 & 7 & 35 & $5 \times 10^{-5}-1 \times 10^{-1}$ & $5 \times 10^{-5}$ \\
10 & 33 & 63 & 8 & 36 & $5 \times 10^{-4}-1 \times 10^{-1}$ & $8 \times 10^{-5}$ \\
\hline
\end{tabular}

Calibration curve

Experiments were conducted a number of times to check the reproducibility of the results. EMFs were plotted against log of activities of cerium ions and calibration curves were drawn for five sets of experiments. A standard deviation of $\pm 0.9 \mathrm{mV}$ was observed. A representative calibration curve using the electrode 6 is shown in Figure 1. The limit of detection $\left[3 \times 10^{-5} \mathrm{M}\right]$ was calculated according to IUPAC recommendations from the intersection of two extrapolated linear portions of the curve ${ }^{19,20}$.

The electrode response was quite reproducible over the lifetime of the electrode. The sensing behavior of the membrane remains unchanged when potentials are measured from low to high or high to low concentrations. The electrode could be used for at least four 
months without any significant divergence. The electrode was kept in water, when not in use, and was equilibrated with $0.1 \mathrm{M} \mathrm{Ce}^{3+}$ solution for 2 hours before use.

\section{Influence of the concentration of internal solution}

Electrode responses were measured by changing the internal filling solution from $1 \times 10^{-1} \mathrm{M}$ to $1 \times 10^{-3} \mathrm{M}$ (Figure 2). It was found that the variation in the concentration of the internal solution does not cause any significant difference in the potential response, except for an expected change in the intercept of the resulting curve. The concentration of the internal solution as $1 \times 10^{-1} \mathrm{M}$ is quite appropriate for the functioning of the electrode system.

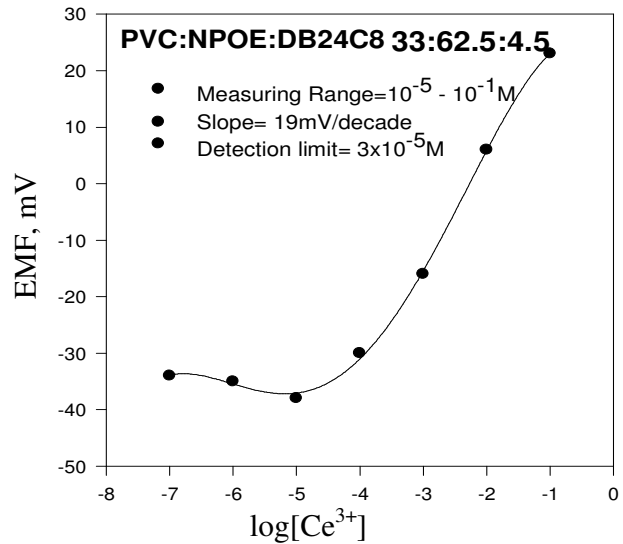

Figure 1. Calibration curve for $\mathrm{Ce}(\mathrm{III})$ selective electrode based on DB24C8.

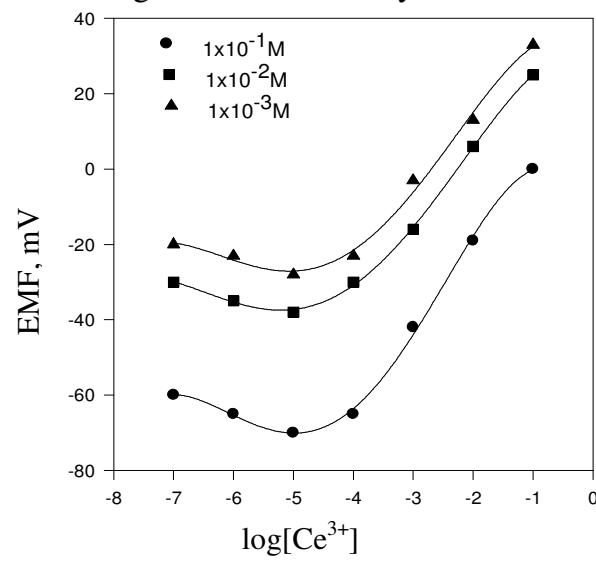

Figure 2. Effect of internal solution on potential response of the $\mathrm{Ce}(\mathrm{III})$-selective electrode based on DB24C8

\section{pH dependence of the electrode}

It is very important to find out the $\mathrm{pH}$ range where the electrode can work without interference from hydrogen ions present in aqueous solutions. The $\mathrm{pH}$ dependence of the sensor was tested by using $1.0 \times 10^{-2} \mathrm{M}$ and $1.0 \times 10^{-3} \mathrm{M} \mathrm{Ce}^{3+}$ solutions over a $\mathrm{pH}$ range of 2.0 to 11.0 (Figure 3). The $\mathrm{pH}$ was adjusted by the addition of small drops of hydrochloric acid $(0.1 \mathrm{M})$ or sodium hydroxide $(0.1 \mathrm{M})$, as required. It is clear from Figure 3 that the emf remains constant from $\mathrm{pH} 4.0$ to 8.0 and 3.5 to 7.5 for $1 \times 10^{-2} \mathrm{M}$ and $1 \times 10^{-3} \mathrm{M} \mathrm{Ce}^{3+}$ ion concentrations, respectively. Beyond this $\mathrm{pH}$, a drift in emf is observed which may be due to the formation of hydroxy complexes of $\mathrm{Ce}^{3+}$ at higher $\mathrm{pH}$ and due to protonation of oxygen atoms of DB24C8 at lower $\mathrm{pH}$.

\section{Effect of partially non-aqueous media}

The functioning of the electrode was also investigated in partially non-aqueous media using methanol-water, acetone-water and DMSO-water mixtures. It was found that the assembly works well up to $20 \%$ non-aqueous content without showing any appreciable change in the working concentration range or slope (Figure 4). In acetone medium, a significant change in emf, slope, measuring range and detection limit is observed. This may be due to the dynamic complex formation and decomplexation between $\mathrm{DB} 24 \mathrm{C} 8$ and $\mathrm{Ce}(\mathrm{III})$ in the water-acetone mixture.

\section{Potentiometric selectivity}

One of the most important characteristics of a membrane sensor is its response for the primary ion in presence of other ions, which is measured in terms of the potentiometric selectivity coefficient $\left(K_{A, B}^{\text {Pot }}\right)$. The fixed interference method (FIM) at the interfering ion 
concentration $1 \times 10^{-3} \mathrm{M}$ is adopted in the present case to determine the selectivity coefficient data. The selectivity coefficient is calculated from these two extrapolated linear segments of the calibration curve. Following expression is used for this purpose:

$$
K_{A, B}^{P o t}=\frac{a_{A}}{\left(a_{B}\right)^{z_{A} / z_{B}}}
$$

Where, $a_{A}$ is the activity of the primary ion and $a_{B}$ the activity of the interfering ion. $\mathrm{z}_{A}$ and $\mathrm{z}_{B}$ are their respective charges.

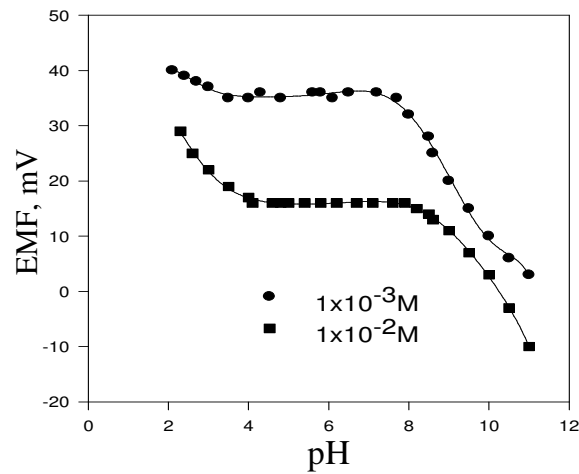

Figure 3. Effect of $\mathrm{pH}$ on the response of Ce(III)-selective electrode based on DB24C8.

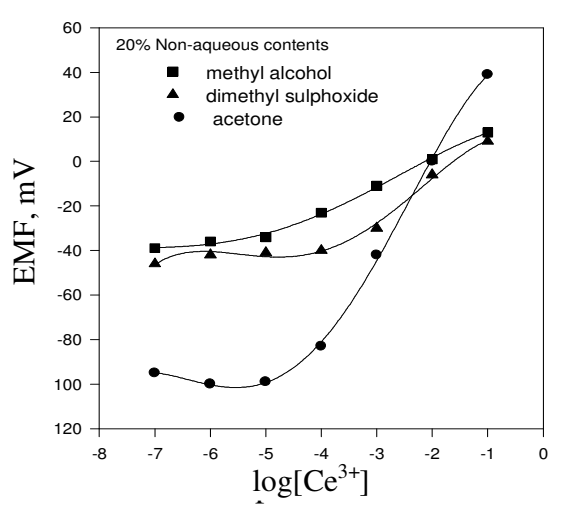

Figure 4. Effect of partially non-aqueous media on the response of $\mathrm{Ce}(\mathrm{III})$-selective electrode based on DB24C8.

Table 2. Selectivity coefficient values for Ce(III)-selective electrode based on DB24C8 as calculated by FIM method.

\begin{tabular}{cccccc}
\hline \multirow{2}{*}{$\begin{array}{c}\text { Interfering ion } \\
(B)\end{array}$} & \multicolumn{5}{c}{ Selectivity Coefficient values $\log \left(K_{A, B}^{P o t}\right)$} \\
\cline { 2 - 6 } & Present & \multicolumn{5}{c}{ Previous reports } \\
\cline { 2 - 6 } & study & {$[4]$} & {$[5]$} & {$[6]$} & {$[7]$} \\
\hline $\mathrm{Nd}^{3+}$ & -0.4 & - & - & - & - \\
$\mathrm{Sm}^{3+}$ & -0.6 & - & - & - & - \\
$\mathrm{Eu}^{3+}$ & -0.6 & - & - & - & - \\
$\mathrm{Pr}^{3+}$ & -0.7 & - & - & - & - \\
$\mathrm{Tb}^{3+}$ & -0.8 & - & - & - & - \\
$\mathrm{Dy}^{3+}$ & -0.7 & - & - & - & - \\
$\mathrm{Yb}^{3+}$ & -1.2 & - & - & - & - \\
$\mathrm{La}^{3+}$ & -0.3 & -1.3 & -2.4 & -1.4 & -2.5 \\
$\mathrm{Fe}^{3+}$ & -0.3 & - & - & - & - \\
$\mathrm{Mg}^{2+}$ & -0.4 & -2.5 & - & -2.4 & -6.0 \\
$\mathrm{Ca}^{2+}$ & -0.6 & -1.6 & - & -2.3 & -6.0 \\
$\mathrm{Cu}^{2+}$ & -0.6 & -1.4 & -4.2 & -2.3 & -2.4 \\
$\mathrm{~Pb}^{2+}$ & -0.7 & -1.9 & -2.0 & -2.3 & -2.6 \\
$\mathrm{Hg}^{2+}$ & -0.8 & -4.0 & -4.1 & -2.3 & -2.7 \\
$\mathrm{~K}^{+}$ & -0.7 & - & - & - & - \\
$\mathrm{Ag}^{+}$ & -1.2 & -1.5 & -3.9 & -4.0 & -2.8 \\
\hline
\end{tabular}


The resulting $\log \left(K_{A, B}^{\text {Pot }}\right)$ values for the proposed $\mathrm{Ce}(\mathrm{III})$-selective electrode are summarized in Table 2. The selectivity coefficients for the previously reported ceriumselective electrodes are also included in Table 2. It can be seen from Table 2 that the electrode has a reasonably good selectivity for $\mathrm{Ce}^{3+}$ ions in the presence of other rare earth metal ions, some alkali, alkaline earth and transition metal ions, which are normally present with cerium(III) in its ores. The selectivity is good in the sense that all the rare earth metal ions have identical sizes and properties. Moreover a comparison between the selectivity coefficients of the proposed electrode with those previously reported for the cerium(III) reveals that the proposed electrode shows almost comparable selectivity, in some cases, to foreign ions.

\section{Analytical application}

The analytical applicability of the sensor was tested by using it as an indicator electrode in the potentiometric titration of $\mathrm{Ce}^{3+}$ ion solution. $50.0 \mathrm{~mL}$ of $\mathrm{Ce}^{3+}$ solution $\left(1 \times 10^{-3} \mathrm{M}\right)$ was titrated against oxalic acid solution $\left(1 \times 10^{-2} \mathrm{M}\right)$. The curve is not a standard sigmoid shaped Figure 5. However, a very good inflection point corresponding to Ce-oxalate stoichiometry is observed which shows that this sensor can be used for determination of $\mathrm{Ce}^{3+}$ ions potentiometrically.

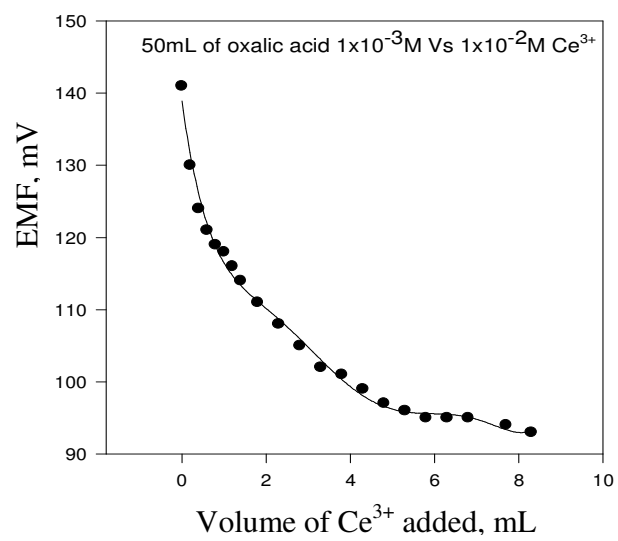

Figure 5. Titration curve of $\mathrm{Ce}(\mathrm{III})$ ions with oxalic acid solution using $\mathrm{Ce}(\mathrm{III})$-selective electrode based on DB24C8.

\section{Lifetime of electrode}

The proposed sensor can be used for at least four months without any significant divergence in results.

\section{References}

1. Wilson C L and Wilson D W, Comprehensive Analytical Chemistry, Vol. 1C; Elsevier: Amsterdam, 1962, 477.

2. Jyothni A and Rao G N, Talanta, 1990, 37, 431.

3. Rao C K, Reddy V K and Reddy T S, Talanta, 1994, 41, 237.

4. Shamsipur M, Yousefi M and Ganjali M R, Anal Chem., 2000, 72, 2391.

5. Shamsipur M, Yousefi M, Hosseini M and Ganjali M R, Anal Lett., 2001, 34, 2249.

6. Karami H, Mousavi M F, Shamsipur M, Yavari I and Alizadeh A A, Anal Lett., 2003, 36, 1065.

7. Akhond M, Najafi M B and Tashkhourian J, Sens Actuators B, 2004, 99, 410. 
8. Pederson C J, J Am Chem Soc., 1967, 89, 7017.

9. Gladilovich D B, Kub SV and Sommer L, Talanta, 1988, 35, 259.

10. Hrdlicka A, Havel J, Moreno C and Valiente M, Anal Sci., 1991, 7, 925.

11. Houk R S, Fassel V A, Flesch G D and Svec H J, Anal Chem., 1980, 52, 2238.

12. Shibata N, Fudagawa N and Kubota M, Anal Chem., 1991, 63, 636.

13. Mazzucotelli A, DePaz. F, Magi E and Frache R, Anal Sci., 1992, 8, 189.

14. Masuda A, Nakamura N and Tanaka T, Geochim Cosmochim Acta, 1973, 37, 239.

15. Marsh S F, Anal Chem., 1967, 39, 641.

16. McCown J J and Larsen J P, Anal Chem., 1961, 33, 1003.

17. Comell D H, Pure Appl Chem., 1993, 65, 2453.

18. Mittal S K, Ashok Kumar S K and Sharma H K, Talanta, 2004, 62, 801.

19. Buck R P and Lindner E, Pure Appl Chem., 1994, 66, 2527.

20. Umezawa Y, Umezawa K and Sato H, Pure Appl Chem., 1995, 67, 507. 


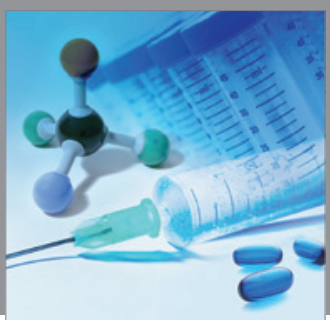

International Journal of

Medicinal Chemistry

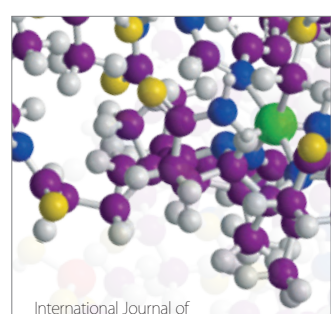

Carbohydrate Chemistry

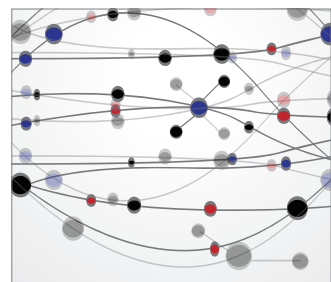

The Scientific World Journal
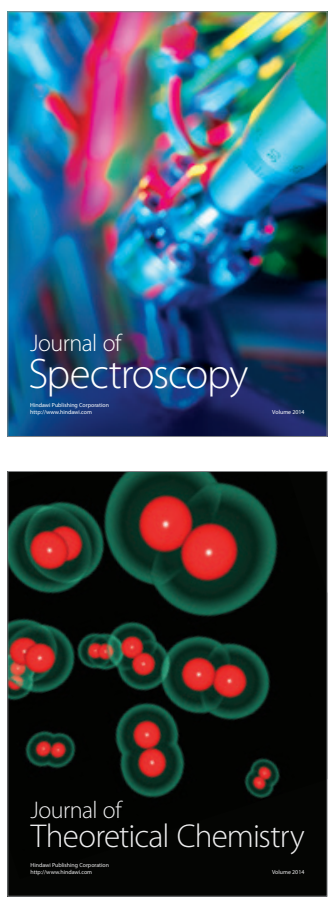
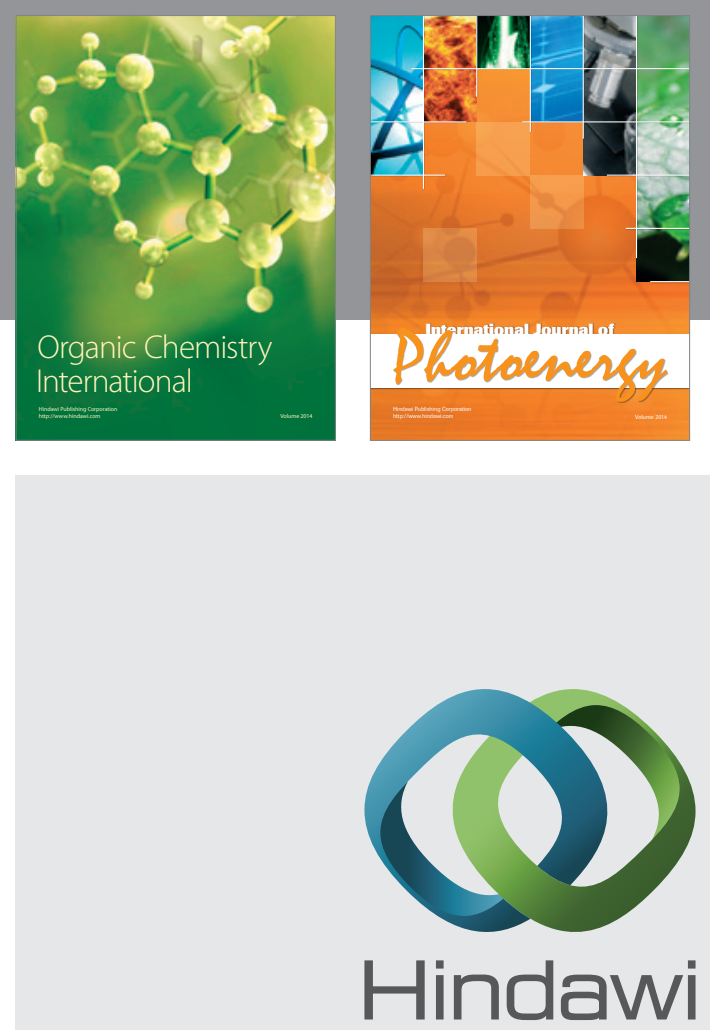

Submit your manuscripts at

http://www.hindawi.com
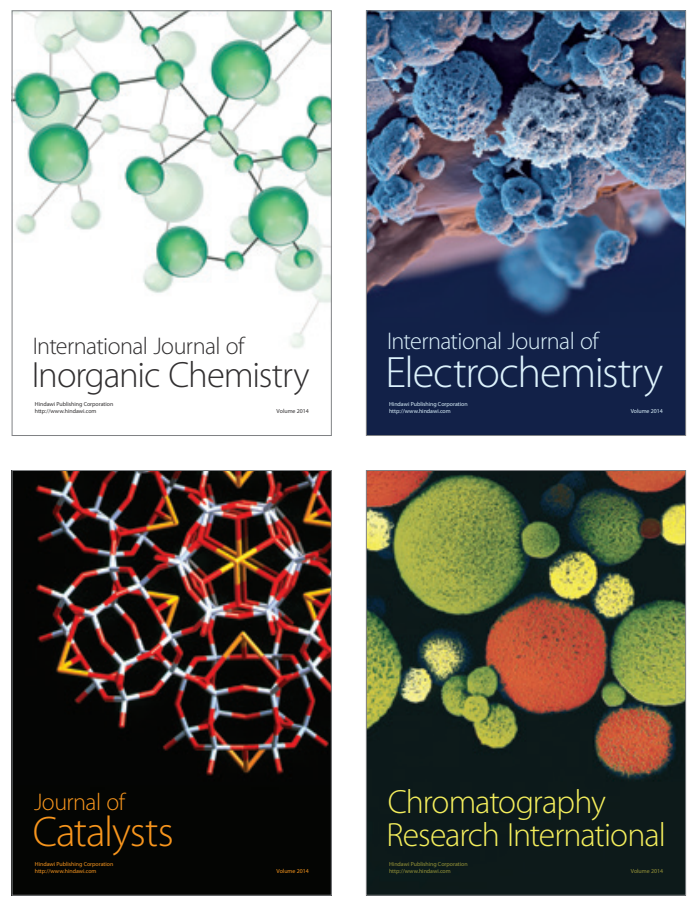
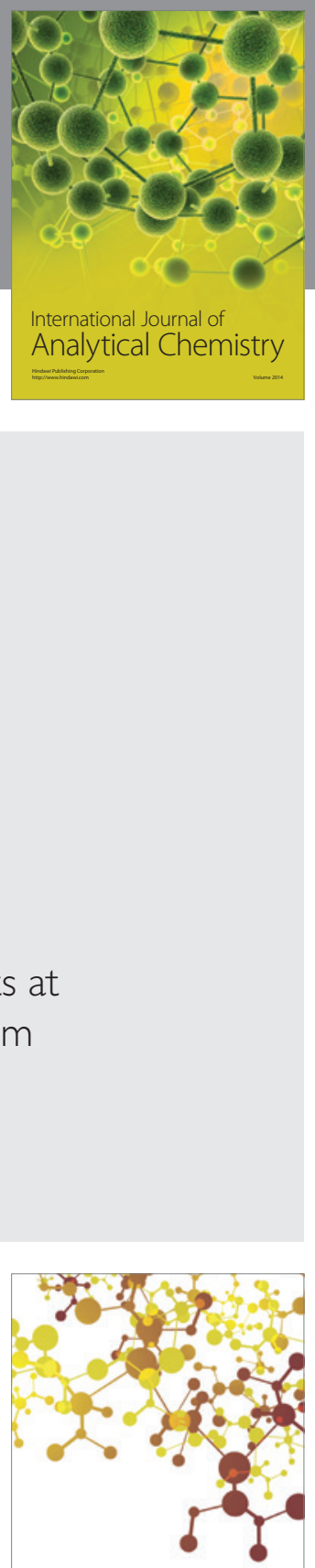

Journal of

Applied Chemistry
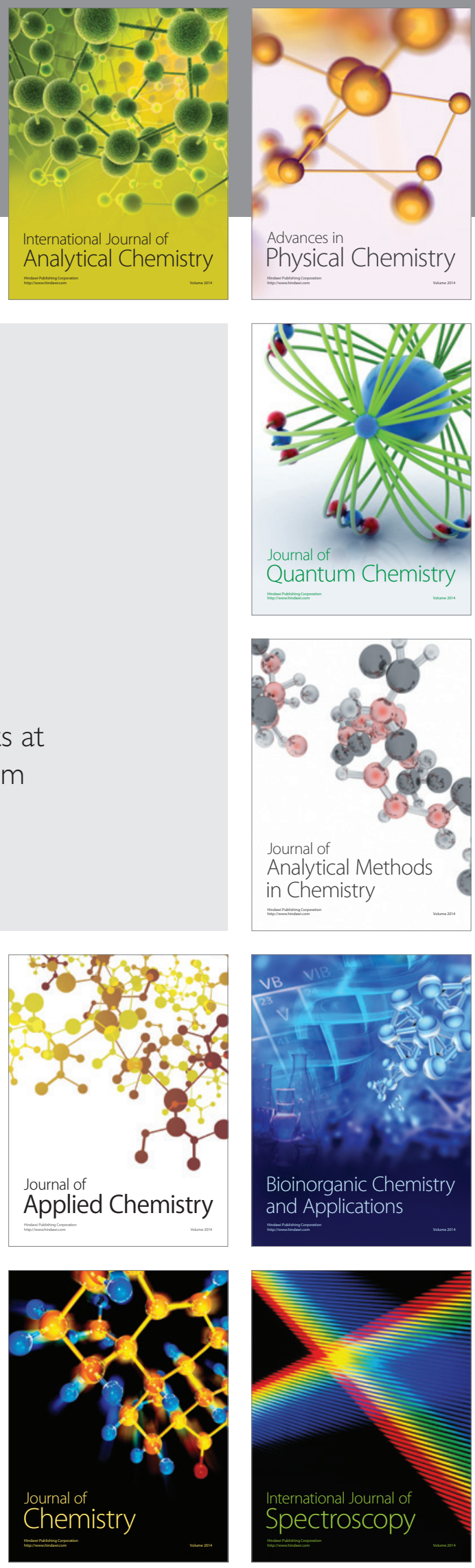